\title{
Análise biomecânica ex vivo de um modelo de haste intramedular de polipropileno para osteossíntese em úmeros de bezerros
}

\author{
[Ex vivo biomechanics assay of a model of polypropylene intramedullary nail \\ for calf humeral osteosynthesis] \\ C.A. De Marval ${ }^{1}$, G.E.S. Alves ${ }^{2}$, E.B. Las Casas $^{3}$, C.G.Costa ${ }^{4}$, J.M.E. Saffar ${ }^{4}$, L.A. Lago ${ }^{2}$ \\ W.T.V. Carvalho ${ }^{5}$, B.B. Leal ${ }^{1}$, R.R. Faleiros ${ }^{2 *}$ \\ ${ }^{1}$ PUCMinas - Betim, MG \\ ${ }^{2}$ Escola de Veterinária - Universidade Federal de Minas Gerais \\ Av. Antônio Carlos, 6627 \\ 31270-901 - Belo Horizonte, MG \\ ${ }^{3}$ Escola de Engenharia - UFMG - Belo Horizonte, MG \\ ${ }^{4}$ Laboratório Robert Hooke - Fundação Centro Tecnológico de Minas Gerais (CETEC), MG \\ ${ }^{5}$ Instituto Federal do Sudoeste de Minas Gerais
}

\begin{abstract}
RESUMO
Foram utilizados 12 pares de úmeros obtidos de bezerros machos da raça Holandesa, com idades entre 15 e 30 dias. Os úmeros esquerdos foram mantidos íntegros, e os direitos foram fraturados de forma oblíqua em sua diáfise, na transição entre os terços médio e proximal. A redução da fratura foi feita pela aplicação intramedular de haste de polipropileno, bloqueada por dois parafusos corticais de aço inoxidável, dispostos transversalmente em cada fragmento ósseo. Seis pares de ossos foram submetidos ao teste de compressão, e seis ao teste de flexão, utilizando-se uma máquina universal de ensaios. Nos testes de compressão, as cargas médias de ruptura foram 738,3N e 473,3N, e nos testes de flexão 322,4N e 117,9N, para os ossos íntegros e fraturados, respectivamente. Comparando-se o grupo de ossos fraturados com o grupo de ossos íntegros, verificou-se que o sistema proposto foi capaz de resistir a 66,4\% das cargas médias quando submetido à compressão, e a 36,6\% quando submetido à flexão. Úmeros fraturados e tratados com haste intramedular de polipropileno apresentaram resistência limitada se comparados aos ossos íntegros.
\end{abstract}

Palavras-chave: bovino, haste bloqueada, polímero, biomaterial, ortopedia

\begin{abstract}
A total of 12 pairs of humeri from male calves 15 to 30 days old were used. The left humeri remained unchanged and the right ones were fractured in the diaphysis between proximal and middle thirds. The fracture was fixed with a polypropylene intramedullary nail interlocked with two steel bone screws crossed along each segment. Six pairs of bones were subjected to a compression test and the others to a flexural test using a universal testing machine. In the compression tests, the mean rupture loads were $738,3 \mathrm{~N}$ and 473,3N, and in the flexural tests they were 322,4N and 117,9N for the intact and fractured bones respectively. Fractured bones fixed with the proposed model were able to resist $66.4 \%$ of the load during compression and 36.6\% during bending when in comparison to intact bones. Fractured humeri treated with polypropylene intramedullary nail showed limited resistance compared to intact ones.
\end{abstract}

Keywords: cattle, interlocking nail, polymer, biomaterial, orthopedics

Recebido em 17 de março de 2010

Aceito em 17 de março de 2011

*Autor para correspondência (corresponding author)

E-mail: faleiros@ufmg.br 


\section{INTRODUÇÃo}

As fraturas ósseas estão entre os problemas médicos mais comuns, pois podem ocorrer em pessoas e animais domésticos de todas as idades. Os cuidados com as fraturas concentram-se na identificação do tipo e da extensão do trauma e na criação de um ambiente biológico que maximize os processos normais de reparação do osso. Um dos principais objetivos do tratamento é evitar as muitas complicações que podem acompanhar a lesão musculoesquelética.

O tratamento da fratura de ossos longos em grandes animais, principalmente o úmero e o fêmur, permanece um desafio para a medicina veterinária devido às grandes massas musculares envolvidas, à dificuldade de imobilização externa da parte proximal dos membros, à impossibilidade de manter os animais sem utilizar o membro afetado para apoio no póscrúrgico e ao elevado custo dos implantes metálicos comumente utilizados (Rakestraw, 1996).

O sistema de haste bloqueada promove satisfatória estabilidade no foco da fratura (McClure et al., 1998) e vem sendo considerado o implante de escolha na ortopedia humana para o tratamento de fraturas cominutivas no fêmur, úmero e tíbia (Zehtab et al., 2004), além de suportar cargas elevadas in vivo, o que permite ao paciente retornar da anestesia com imediato apoio no membro fraturado. Estudos mostram que houve aumento no reparo ósseo de fraturas de tíbia em humanos quando foi utilizada a haste bloqueada de forma semifechada, minimizando o trauma sobre os vasos periosteais e extraósseos, reduzindo, dessa forma, as possibilidades de infecção e otimizando a cicatrização do osso (Nunamaker, 1996).

Em neonatos, a haste bloqueada também constitui uma opção interessante, pois a fina camada cortical do úmero não favorece a aplicação de placas ortopédicas, tratamento até então de escolha para esses ossos (Hamilton e Tulleners, 1980; Ames, 1981; De Marval et al., 2004).

A busca por materiais cada vez mais leves, resistentes, de baixo custo e biocompatíveis tem crescido dia a dia (van der Elst et al., 1999). O polipropileno é o material biocompatível mais utilizado no reparo de lesões da cavidade abdominal em humanos, permanecendo em contato direto com as vísceras, devido à baixa reatividade, que se soma às vantagens de alta resistência e ao baixo custo (Goissis et al., 2001). Além disso, há uma variedade de fios cirúrgicos feitos de polipropileno, o que reflete, mais uma vez, sua biocompatibilidade.

Os objetivos deste trabalho foram desenvolver um sistema para imobilização interna de fraturas em ossos longos com uso de um polímero biocompatível na forma de haste bloqueada intramedular e verificar, ex vivo, as propriedades físicas deste sistema, comparando ossos íntegros com aqueles fraturados e submetidos à imobilização com a técnica proposta.

\section{MATERIAL E MÉTODOS}

Foram utilizados 12 pares de úmeros obtidos de bezerros machos da raça Holandesa, com idade entre 15 e 30 dias, necropsiados em Setor de Patologia Escola e que participaram de um experimento sobre hidratação após diarreia osmótica induzida. O procedimento experimental foi aprovado pelo Comitê de Ética em Experimentação Animal da UFMG (protocolo 145/04). Imediatamente após o abate, os ossos foram dissecados dos tecidos moles adjacentes, acondicionados em sacos plásticos e conservados por congelamento a $-20^{\circ} \mathrm{C}$.

Foram utilizadas hastes de polipropileno (SafPlast, Belo Horizonte, MG) adquiridas em lojas especializadas em material plástico para indústrias. A haste utilizada no experimento, de diâmetro de 13mm, segundo o fabricante, possuía resistência de tensão de ruptura à tração de 4300-5500 PSI, tensão de ruptura à compressão de 8500-10000 PSI e tensão de ruptura à flexão de 6000-8000 PSI.

Depois de descongelados à temperatura ambiente por 12 horas, os úmeros direitos foram seccionados em sua diáfise, na transição entre os terços médio e proximal, de forma a simular uma fratura oblíqua. A incisão foi realizada em sentido caudoproximal para crâniodistal com serra em fita, em um ângulo de aproximadamente 30 graus em relação ao eixo longitudinal do osso, sendo o ponto inicial de corte localizado $1,0 \mathrm{~cm}$ distal ao colo da cabeça do úmero, em sua face caudal. Os úmeros esquerdos foram mantidos íntegros para serem submetidos aos testes como grupo-controle. 
A redução da fratura foi feita pela aplicação retrógrada da haste de polipropileno, após a abertura do canal medular com uma broca de aço do mesmo diâmetro. Essa abertura foi realizada apenas na extensão do canal medular no fragmento distal e, no proximal, se entendeu até produzir abertura no tubérculo maior do úmero. Para bloqueio da haste, foram utilizados dois parafusos de aço inoxidável (4,5mm de diâmetro e $50 \mathrm{~mm}$ de comprimento) em cada fragmento, colocados de forma transversal ao eixo do osso, inseridos na face lateral de forma a perfurar a cortical de ambos os lados. Esse procedimento foi realizado após perfuração tanto da cortical quanto da haste com uma broca de aço $(3,2 \mathrm{~mm}$ de diâmetro).

Os testes físicos foram realizados no Laboratório Robert Hooke da Fundação Centro Tecnológico de Minas Gerais (CETEC). Depois de divididos aleatoriamente em dois grupos de seis pares, os ossos íntegros e instrumentados foram submetidos a dois tipos de testes: compressão e flexão, em uma máquina universal de ensaios (Riehle Testing Machine, American Machine and Metals Inc.) com capacidade para $60.000 \mathrm{~kg}$ e velocidade de 0 a $5 \mathrm{~cm} / \mathrm{min}$.

Para os testes de flexão, os ossos foram apoiados sobre uma base de madeira maciça, em forma de

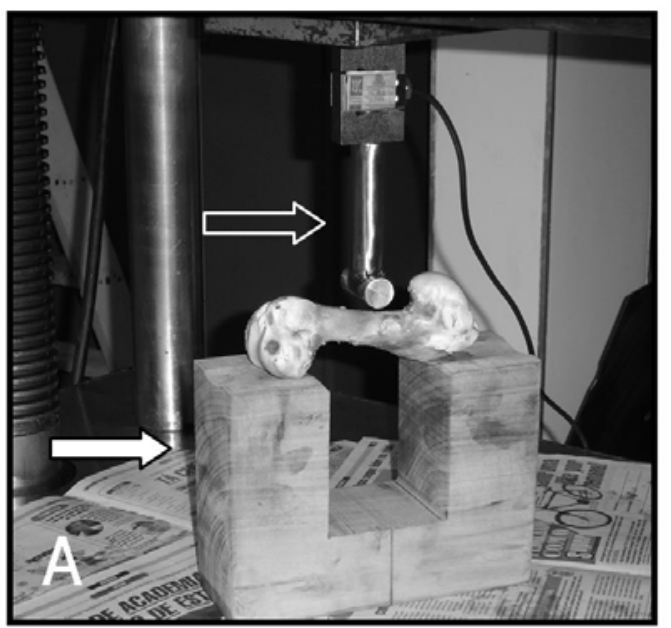

U, e a força aplicada no centro da diáfise por meio de um pistão até a fratura da amostra (Fig. 1A). À extremidade do pistão aplicador, foi acoplado um leitor de precisão, que obtinha os valores de forma digital. O ponto de aplicação da força pela máquina universal de ensaios nos testes de flexão sempre foi o terço médio da diáfise, na face caudal do osso, para tentar simular a situação mais real possível. Dessa forma, considerou-se como teste de flexão de três pontos.

Para os testes de compressão, a força foi aplicada ao longo do eixo da amostra no sentido próximodistal. Assim, o osso teve que ser mantido perpendicular à base da máquina. Para isso, foram desenvolvidos suportes feitos com uma chapa metálica de aproximadamente $20 \mathrm{~cm}^{2}$, sobre a qual foi soldado um tubo metálico de $100 \mathrm{~mm}$, com $5 \mathrm{~cm}$ de altura (Fig. 1B). Nas extremidades ósseas, foram colocadas bases de polimetilmetacrilato, que se adaptava às irregularidades ósseas nas duas extremidades. Essas bases foram moldadas em canos de PVC, onde os ossos eram imersos. Na extremidade do pistão que aplicava a força, foi adaptado um sensor ligado a um aparelho que fazia a leitura da carga aplicada.

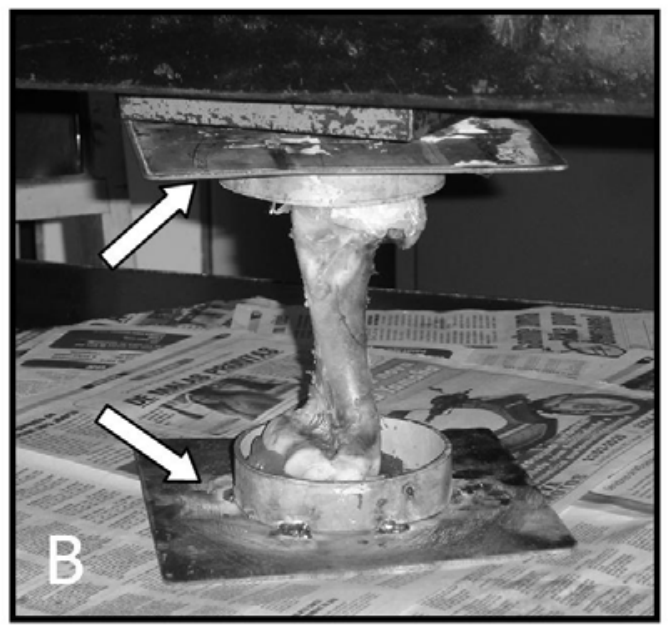

Figura 1. Úmeros de bezerros submetidos a testes físicos em máquina de ensaios universal. A - Teste de flexão. Observar o suporte de madeira (seta branca) e o pistão aplicador de carga na diáfise (seta aberta). B - Teste de compressão. Observar as bases metálicas (setas brancas) nas extremidades ósseas. 
Os testes iniciavam-se quando a força era aplicada sobre as amostras. A força de ruptura foi considerada como a carga máxima registrada imediatamente antes do momento em que a amostra falhava em resistir à pressão exercida pela máquina. Após este momento, apesar de a amostra apresentar resistência menor, o teste teve continuidade até que houvesse completa falha estrutural, sendo assim possível verificar todos os pontos de fragilidade das amostras.

Os valores médios para as variáveis dos ensaios mecânicos dos ossos íntegros e fraturados foram analisados por meio do teste $t$ pareado, sendo considerado o nível de significância de $\mathrm{P} \leq 0,05$ (Sampaio, 1998).

\section{RESULTADOS E DISCUSSÃO}

O método de conservação por congelamento foi semelhante ao utilizado por Galuppo et al. (2002) e por Dallabrida et al. (2005), aparentando ser eficiente em manter as características normais do osso. A ausência de tecidos moles facilitou o manuseio dos ossos e a conseguinte instrumentação.

Não houve maiores dificuldades em promover a fratura óssea, para a inserção da haste - cuja saída sempre ocorreu sobre o tubérculo maior do úmero -, nem para a colocação dos parafusos. A localização do ponto de perfuração sobre o tubérculo maior sempre foi feita utilizando-se o alinhamento da haste com o fragmento distal, uma vez que este é o fator limitante, pois não existe mobilidade entre esse conjunto devido ao menor diâmetro dessa região óssea quando comparado com a região proximal do úmero. Isso significa que a haste pode estar em posições variadas no segmento proximal, mas em apenas uma posição na região distal. Caso isso não fosse respeitado, tanto ex vivo quanto in vivo, não ocorreria coaptação nem alinhamento satisfatório dos fragmentos.

Não houve maiores dificuldades para a inserção dos parafusos, pois não havia limitações de espaço para visualização e manipulação. Quando havia dúvidas sobre a precisão do furo, a haste era facilmente removida para a conferência.

A máquina universal de ensaios utilizada mostrou-se adequada para os testes. Os adaptadores metálicos confeccionados e acoplados às extremidades ósseas foram mantidos na posição vertical e promoveram a congruência dos ossos com o pistão da máquina. Para o teste de flexão, a base fixa de madeira manteve os ossos estáveis durante os testes, impedindo sua movimentação quando era aplicada a força.

O suporte metálico usado para sustentação dos ossos nos testes de compressão na máquina universal de ensaios foi fundamental, pois sem ele não seria possível manter o osso na posição vertical. $\mathrm{O}$ úmero bovino possui uma série de irregularidades que não permitiriam boa acomodação do pistão sobre as extremidades, e isso promoveria o desnivelamento da peça. $\mathrm{O}$ polimetilmetacrilato foi imprescindível para fixar o osso ao adaptador metálico, que também não era congruente com o osso. Esse material mostrou-se de fácil adaptação, manuseio e resistência. Outros pesquisadores já utilizaram o mesmo material para fixar ossos para a realização de testes de compressão (Galuppo et al., 2002; Dallabrida et al., 2005).

Nos testes de flexão em ossos íntegros, a falência estrutural ocorreu sempre longitudinalmente ao longo da diáfise. Nos ossos submetidos à técnica de redução da fratura, observou-se uma pequena fragmentação óssea caudal, no ápice da linha de fratura do fragmento distal, contudo a falência estrutural sempre ocorreu na haste de polipropileno. Durante a flexão, a aplicação das forças na face caudal do membro gerou uma força de tensão na superfície cranial e uma força de compressão na superfície caudal (Hulse e Hylman, 1993). Essa dinâmica ocorre em ossos íntegros, mas, quando se tratou de um osso submetido à técnica de redução de fratura, a tensão transformou-se em afastamento dos fragmentos, e a compressão em um encontro deles, ocorrendo um choque que promoveu a fratura do ápice do fragmento distal em todos os ossos testados.

Todas as hastes submetidas à flexão romperamse no exato local onde havia um parafuso transfixando-as e no ponto mais próximo do foco da fratura. Verificou-se, assim, que as interfaces haste parafuso representaram os pontos críticos do sistema, uma vez que, na flexão, a falha sempre ocorreu nessas regiões. Além disso, a ruptura sempre deu-se nos pontos mais próximos ao foco da fratura, possivelmente por ter 
associado um enfraquecimento da haste pelo parafuso ao fato de haver maior mobilidade do sistema, nessa região.

Nos testes de compressão, os ossos íntegros sempre cederam nas metáfises, e nunca nas diáfises. Já nos instrumentados, a falha ocorreu em pontos variados da metáfise, sempre na linha criada pela sequência de colocação dos parafusos no osso. Em todos os casos, houve o deslizamento dos fragmentos na linha de fratura por sua obliquidade, com o fragmento proximal projetando-se cranialmente antes da ruptura. O fato de os ossos íntegros sempre cederem nas placas de crescimento nos testes de compressão deve-se a esta ser a região de menor resistência dos ossos de animais jovens, uma vez que sua base mineral é mínima, predominando a composição orgânica.

Na compressão dos ossos instrumentados, muito antes de ocorrer a falha, havia um deslizamento dos fragmentos. $\mathrm{O}$ fato de a falha sempre ocorrer na região óssea próxima aos parafusos indica que a perfuração, associada à transferência de forças para o osso pelos parafusos, forma uma linha de enfraquecimento. Esse fato foi observado por Widjaja e Hartung (2001), quando realizaram testes biomecânicos em fêmures humanos embalsamados e submetidos à técnica de haste bloqueada. Nos resultados obtidos nos testes de compressão, as forças de ruptura foram, em média, 738,3 N e 473,3N, e para as provas de flexão, $322,4 \mathrm{~N}$ e $117,9 \mathrm{~N}$, para os ossos íntegros e fraturados, respectivamente (Tab. 1).

Tabela 1. Forças de ruptura e percentuais de resistência dos úmeros bovinos fraturados em relação aos íntegros nos testes de compressão e flexão

\begin{tabular}{|c|c|c|c|c|c|c|c|}
\hline \multirow{3}{*}{ Animal } & \multicolumn{7}{|c|}{ Carga máxima à ruptura } \\
\hline & \multicolumn{3}{|c|}{ Testes de compressão } & \multirow{2}{*}{ Animal } & \multicolumn{3}{|c|}{ Testes de flexão } \\
\hline & Fraturado & Íntegro & Percentual & & Fraturado & Íntegro & Percentual \\
\hline 1 & 560 & 720 & 77,8 & 7 & 127,4 & 297,6 & 42,8 \\
\hline 2 & 570 & 980 & 58,2 & 8 & 83,8 & 267,8 & 31,3 \\
\hline 3 & 440 & 960 & 45,8 & 9 & 136,9 & 347,2 & 39,4 \\
\hline 4 & 400 & 640 & 62,5 & 10 & 126,7 & 328,4 & 38,6 \\
\hline 5 & 450 & 570 & 78,9 & 11 & 110,9 & 342,3 & 32,4 \\
\hline 6 & 420 & 560 & 75,0 & 12 & 121,4 & 351,1 & 34,6 \\
\hline Média & 473,3 & 738,3 & 66,4 & Média & 117,9 & 322,4 & 36,5 \\
\hline DP & 73,1 & 188,5 & 13,2 & DP & 18,7 & 33,1 & 4,5 \\
\hline $\mathrm{CV}$ & 15 & 26 & 20 & $\mathrm{CV}$ & 16 & 10 & 12 \\
\hline
\end{tabular}

A comparação, em percentual de resistência, demonstrou que o sistema que utilizou a haste de polipropileno apresentou maior resistência nos testes de compressão que nos de flexão. Este resultado era esperado pelo fato de que, quando se tem a carga aplicada no eixo axial, além da resistência da haste, que é muito maior no seu eixo longitudinal, tem-se ainda o apoio entre os fragmentos ósseos na linha de fratura. A partir do momento em que a força é aplicada na diáfise óssea, quase toda a resistência é oferecida pela haste.

Resultados inversos foram obtidos por Galuppo et al. (2002), que realizaram testes semelhantes em um sistema de haste bloqueada em metacarpos de equinos. A diferença é que a haste utilizada pelos pesquisadores era de aço inoxidável, e os ossos submetidos ao sistema eram osteoectomizados. Quando submetidos à compressão, a haste era muito mais resistente que o osso, e, pelo fato de estes não estarem em contato, devido à osteoectomia, o osso cedia muito antes da haste. Já nos testes de flexão, a resistência era praticamente toda oferecida pela haste, proporcionando maior resistência à flexão quando comparada à compressão.

Ao se comparar o grupo de ossos fraturados com o de ossos íntegros, verificou-se que o modelo de haste bloqueada foi capaz de resistir a apenas $66,4 \%$ das cargas médias, quando submetidos à compressão, e a 36,6\%, quando submetidos à flexão (Tab. 1). Em termos relativos, tais resultados indicaram que a haste de polipropileno ofereceu resistência apenas limitada para suportar forças de flexão in vivo. Contudo, a suposição de que tal resistência seja insuficiente ainda é prematura, uma vez que, no estudo ex vivo, as forças são aplicadas de forma isolada e 
apenas nos pontos de contato da máquina com a estrutura óssea, ou seja, de forma muito distinta do que acontece no animal vivo. Mais ainda, os testes aqui realizados não consideraram a resistência dos tecidos moles adjacentes ao úmero. Ao compararem metacarpianos humanos íntegros com semelhantes submetidos a cinco modelos de osteossíntese (Ohara et al., 1994) demonstraram que o melhor modelo (placa e parafuso) suportou entre 30 a $50 \%$ das cargas suportadas pelos controles.

\section{CONCLUSÕES}

O modelo de haste intramedular de polipropileno bloqueada por parafusos de aço inoxidável ofereceu resistência limitada aos úmeros fraturados quando esses foram comparados com úmeros íntegros. Novos estudos se tornam necessários para determinar se tal resistência seria suficiente para sustentar a imobilização de forma a permitir consolidação óssea em fraturas diafiseais em úmeros de bezerros jovens.

\section{AGRADECIMENTOS}

À Pró-Reitoria de Pesquisa da UFMG e à FAPEMIG, pelo apoio financeiro.

\section{REFERÊNCIAS BIBLIOGRÁFICAS}

AMES, N.K. Comparison of methods for femoral fracture repair in young calves. J. Am. Vet. Med. Assoc., v.179, p.458-459, 1981.

DALLABRIDA, A.L.; SCHOSSLER, J.E.; AGUIAR, E.S.V. et al. Biomechanical analysis ex vivo of two osteosynthesis methods for transversal diaphyseal fracture in canine femur. Cienc. Rural, v.35, p.116-120, 2005.

DE MARVAL, C.A.; OLIVEIRA, H.P.; ALVES, G.E.S. et al. Redução de fratura de rádio e ulna em bezerro neonato utilizando-se placa óssea de neutralização associada à imobilização externa com gesso e muleta de Thomas modificada. Braz. J. Vet. Res. Anim. Sci., v.41, p.249-250, 2004.

GALUPPO, L.D.; STOVER, S.M.; ALDRIDGE, A. et al. An in vitro biomechanical investigation of an MP35N intramedulary interlocking nail system for repair of third metacarpal fractures in adult horses. Vet. Surg., v.31, p.211-225, 2002.
GOISSIS, G.; SUZIGAN, S.; PARREIRA, D.R. et al. Malhas de polipropileno recobertas com colágeno polianiônico ou com dupla camada com poli(cloreto de vinila) para a reconstrução da parede abdominal. Rev. Bras. Eng. Biom., v.17, p.69-78, 2001.

HAMILTON, G.F.; TULLERNERS, E.P. Transfixation pinning of proximal tibial fractures in calves. J. Am. Vet. Med. Assoc., v.176, p.725727, 1980.

HULSE, D.; HYMAN, B. Fracture biology and biomechanics, In: SLATTER, D. (Ed.). Textbook of small animal surgery. Philadelphia: W.B. Saunders, 1993. p. 1595-1602.

McCLURE, S.R.; WATKINS, J.P.; ASHMAN, R.B. In vitro evaluation of intramedullary interlocking nail fixation of transverse femoral osteotomies in foals. Vet. Surg., v.27, p.29-36, 1998

NUNAMAKER, D.M. Orthopedic implant failure, In: NIXON, A.J. (Ed.). Equine fracture repair. Philadelphia: W.B. Saunders, 1996. p.350-353.

OHARA, G.H.; ROSSI, J.D.M.B.; ALVARENGA, L. et al. Estudo experimental de cinco modelos de osteossíntese em ossos metacarpianos humanos. Rev. Bras. Ortop., v.29, p.211-217, 1994.

RAKESTRAW, P.C. Fracture of humerus. Vet. Clin. N. Am.: Food Anim. Pract., v.12, p.153168, 1996.

SAMPAIO, I.B.M. Estatística aplicada à experimentação animal. Belo Horizonte: FEPMZV, 1998. p.221.

VAN DER ELST, M.; KLEIN, C.P.A.T.; DE BLIECK-HOGERVORST, J.M. et al. Bone tissue response to biodegradable polymers used for intra medullary fracture fixation: A long-term in vivo study in sheep femora. Biomaterial, v.20, p.121-128, 1999.

WIDJAJA, W.; HARTUNG, C. Biomechanical comparison of different fixations of femurinterlocking-nails. Clin. Biomech., v.16, p.702705, 2001.

ZEHTAB, M.J.; AHDI, K.; SADAT, M.M. Ender nail: is the old implant effective today? Arch. Iranian Med., v.7, p.217-221, 2004. 